\title{
Tei index of myocardial performance in conscious healthy Beagles
}

\author{
Índice de rendimiento miocárdico Tei en Beagles conscientes y clínicamente sanos
}

\author{
MG Sousa ${ }^{a}$, GB Pereira-Neto ${ }^{a}$, BC Brüler $^{\mathrm{a}}$, D Paulino-Junior ${ }^{\mathrm{a}}$, JPE Pascon ${ }^{\mathrm{a}}$, \\ FN Gava ${ }^{c}$, R Carareto ${ }^{a}$, AA Camachoc
}

\begin{abstract}
The Tei index of myocardial performance is a noninvasive echocardiographic parameter that combines systolic and diastolic time intervals to assess global cardiac performance. It was demonstrated to be a reliable indicator of myocardial dysfunction in dogs with varying clinical conditions. Because only a few studies focused on the measurement of the index in healthy dogs, this cross-sectional study was conceived to investigate how it performs in a large population of clinically healthy Beagle dogs. Our results showed no correlation between the index and body weight, heart rate, and several standard echocardiographic measures which are estimates of preload and afterload. There was no difference between de index calculated for males or females. Also, results indicated strong intra-observer and inter-observer correlations. In conclusion, the Tei index was shown to perform independently of loading conditions, besides being a straightforward and easily reproducible parameter.

Key words: echocardiography, cardiac function, Doppler, dog.
\end{abstract}

RESUMEN. El índice de rendimiento miocárdico es un parámetro ecocardiográfico no invasivo que combina intérvalos de tiempo sistólico y diastólico para evaluar el rendimiento cardiaco total. Se ha demostrado que es un indicador fiable de disfunción miocárdica en perros con diferentes condiciones clínicas. Debido a que pocos estudios se centraron en la medición de este índice en perros sanos, este estudio transversal fue concebido para investigar este rendimiento en una gran población de perros Beagle clínicamente sanos. Nuestros resultados no muestran correlación entre el índice y el peso corporal, la frecuencia cardiaca, y varias medidas ecocardiográficas que son estimaciones estándar de precarga y poscarga. No hubo diferencia entre machos y hembras para el índice calculado. Además, los resultados indicaron notorias correlaciones intraobservador e interobservador. En conclusión, el índice de Tei se mostró como un parámetro independiente de las condiciones de la carga, que además de ser fácil de calcular también es un parámetro de fácil reproducción.

Palabras clave: ecocardiografía, función cardíaca, Doppler, perros.

\section{INTRODUCTION}

Since echocardiography became the standard non-invasive method to assess cardiac structures and function, several echocardiographic indices have been proposed for the evaluation of cardiac remodeling and functional status. The Doppler-derived Tei index of myocardial performance was first described in 1995 as a convenient method that combines systolic and diastolic time intervals to assess global ventricular function (Tei 1995). Some of its supposed advantages include being easily obtained, its reproducibility, as well as its heart rate and arterial blood pressure independency (Pellet et al 2004).

The Tei index, which consists of the sum of isovolumic contraction time and isovolumic relaxation time divided by

\footnotetext{
Accepted: 01.10.2015.

aDepartment of Veterinary Medicine, Federal University of Paraná, Paraná, Brazil.

${ }^{\mathrm{b}}$ College of Agronomy and Veterinary Medicine, University of Brasília, Brasília, DF, Brazil.

${ }^{\mathrm{C} C o l l e g e ~ o f ~ A g r i c u l t u r a l ~ a n d ~ V e t e r i n a r y ~ S c i e n c e s, ~ S a ̃ o ~ P a u l o ~ S t a t e ~ U n i-~}$ versity, Jaboticabal, SP, Brazil.

${ }^{\mathrm{d} C o l l e g e}$ of Veterinary Medicine, Federal University of Pampa, Uruguaiana, RS, Brazil.

${ }^{\mathrm{e} C o l l e g e}$ of Veterinary Medicine and Animal Science, Federal University of Tocantins, Araguaína, Tocantins, Brazil

*Corresponding author: MG Sousa; Rua dos Funcionários, 1540, CEP

80035-050,Curitiba, Paraná, Brazil; marlos98@ufpr.br
}

ventricular ejection time, has been shown to be significantly correlated with important cardiac variables, such as the diastolic peak (-dP/dt) and tau, in people with ischemic heart disease (Tei et al 1997). Thus, it is reasonable to consider its applicability as a reliable method for evaluation of left ventricular function, in addition to its prognostic value in patients with a failing heart.

The theoretical aspects of the index have been evaluated in people. Studies documented that the higher values of the index, mainly due to prolongation of isovolumic intervals and/or shortening of ejection time, are suggestive of a worse prognosis in individuals with heart failure, acute myocardial infarction, pulmonary hypertension, and amyloidosis as compared to healthy control subjects (Pellet et al 2004). Also, it seems that the Tei index may aid in establishing a prognosis regarding cardiac rejection in post-transplant pediatric patients (Mooradian et al 2000). In oncology patients undergoing chemotherapy, this myocardial performance index seem to be a sensitive, precise and easy-to-calculate method for the early identification of myocardial disturbances in individuals treated with moderate doses of anthracyclines (Ishi et al 2000). When normal and mitral-insufficient dogs were compared, Teshima et al (2007) documented higher values of the Tei index, and also found that it significantly increased when clinical signs owing to heart failure became more severe. Regarding its use in prognostication, an investigation that included dogs with parvoviral enteritis found higher values of the 
Tei index in survivors as compared to the non-surviving animals. Curiously, the sensitivity and specificity of the index to predict mortality in that study was higher than those attained by cardiac troponin I (Kocaturk et al 2012).

Although several studies have investigated the diagnostic use of the myocardial performance index in cardiac diseases, only a few focused on the determination of the index in healthy dogs. Therefore, the aim of this research was to determine how the Tei index performs in a large population of conscious healthy dogs, as well as to assess its correlation with some standard non-invasive estimates of preload and afterload.

\section{MATERIALS AND METHODS}

\section{ANIMALS}

Twenty-nine adult Beagle dogs $(12.2 \pm 2.1 \mathrm{~kg})$ of either sex were used. All animals enrolled in the study belonged to the university experimental kennel and were determined to be healthy based on results of physical examinations and ancillary laboratory tests. Also, ECG and echocardiogram were performed in every animal to rule out any cardiac disease that could preclude their inclusion in this investigation. The study was entirely conducted in accordance with guidelines outlined in the National Institutes of Health's Guide for the Care and Use of Laboratory Animals.

\section{ECHOCARDIOGRAPHY}

Every dog was examined with a Doppler transthoracic echocardiograph (Pandion S300, PieMedical, Maastricht, The Netherlands) and a $5.0 \mathrm{MHz}$ mechanical sector transducer. Echocardiographic images were recorded with a simultaneous lead II electrocardiogram for offline measurements.

To facilitate the acquisition of good quality images, hair was clipped between the left $2^{\text {nd }}$ and $7^{\text {th }}$ intercostal spaces. Coupling gel was applied to this area of the thorax just before the echocardiographic examination. With the dog positioned in left lateral recumbency, apical 5-chamber view images were acquired. Continuous wave Doppler was used and care was taken to perform these measurements with the Doppler beam adjusted as parallel as possible to the presumed direction of blood flow. Gain and filter settings were adjusted individually to reduce background noise and result in clear flow signals. To acquire inflow and outflow velocity spectra during the same cardiac cycle, the Doppler line was placed between the mitral inflow and the left ventricular outflow in the apical 5-chamber view. This image was used to measure the mitral closing-to-opening time, which was named interval $A$, as well as the left ventricular ejection time (LVET), which was determined as the duration of the left ventricular outflow profile. These data permitted to calculate the Tei-index as (A-LVET)/
LVET (figure 1) (Tei et al 1997, Madron 2015). At least 3 measurements were made and averaged for each parameter.

Another echocardiographer blinded to results obtained by the first one performed a second acquisition of images and calculation of the Tei index. Also, every animal underwent a second evaluation by the first sonographer within seven days. These additional data were used for calculation of inter-observer and inter-day correlation coefficients, respectively.

\section{STATISTICAL ANALYSES}

Descriptive statistics were used to describe population characteristics. After the data was tested for normality using the Shapiro-Wilk test, Pearson's correlation coefficients were calculated to investigate inter-observer and intra-observer agreements, as well as the correlation between the index and either body weight or heart rate, as well as between the index and several regular echocardiographic parameters. Also, an analysis of variance was used to check for differences between the index calculated for males, females, and all dogs together. The software Prism for Windows v. 5.04 (Graphpad Software, San Diego CA, USA) was used for all statistical analyses, and probability $\mathrm{P}<0.05$ was considered significant.

\section{RESULTS}

Table 1 gives the results of minimum, maximum, mean, median, standard deviation, standard error of the mean, 25 and 75 percentiles, $95 \%$ confidence intervals, and

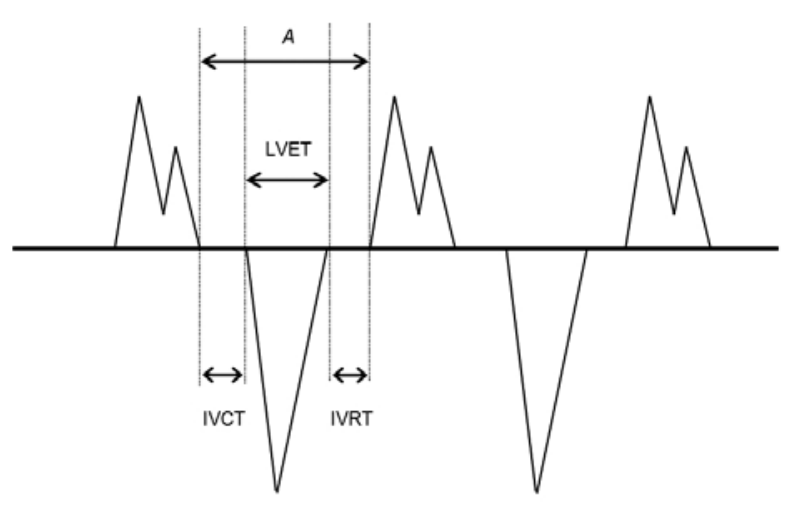

Figure 1. Schematic diagram of mitral and left-ventricular outflow spectra representing the intervals used for calculation of the Tei index. Interval $A$ extends from the cessation to the onset of mitral inflow, and comprises isovolumic contraction time (IVCT), left-ventricular ejection time (LVET), and isovolumic relaxation time (IVRT).

Diagrama esquemático del flujo espectral mitral y del ventrículo izquierdo representando los intervalos utilizados para el cálculo del índice de Tei. El intervalo A se extiende desde el cese de la aparición de flujo de entrada mitral, y comprende el tiempo de contracción isovolumétrica (IVCT), tiempo de eyección ventricular izquierda (LVET), y tiempo de relajamiento isovolumétrico (IVRT). 
Table 1. Descriptive statistics depicting the Tei index of myocardial performance in 29 clinically healthy conscious Beagle dogs. Estadística descriptiva que representa el índice de rendimiento miocárdico Tei en 29 perros Beagles concientes y clínicamente sanos.

\begin{tabular}{llcc}
\hline & $\begin{array}{c}\text { Males } \\
(\mathrm{n}=19)\end{array}$ & $\begin{array}{c}\text { Females } \\
(\mathrm{n}=10)\end{array}$ & $\begin{array}{c}\text { All dogs } \\
(\mathrm{n}=29)\end{array}$ \\
\hline Minimum & 0.0500 & 0.0800 & 0.0500 \\
25\% percentile & 0.1900 & 0.1600 & 0.1750 \\
Median & 0.2500 & 0.2100 & 0.2400 \\
75\% percentile & 0.4000 & 0.3750 & 0.3975 \\
Maximum & 0.5100 & 0.4000 & 0.5100 \\
Mean & 0.2805 & 0.2440 & 0.2692 \\
SD & 0.1360 & 0.1131 & 0.1326 \\
SEM & 0.0312 & 0.0357 & 0.0271 \\
Lower 95\% CI & 0.2150 & 0.1631 & 0.2132 \\
Upper 95\% CI & 0.3461 & 0.3249 & 0.3252 \\
Coefficient of variation & $48.46 \%$ & $46.34 \%$ & $49.27 \%$ \\
\hline
\end{tabular}

SD: Standard deviation; SEM: Standard error of the mean; CI: Confidence interval

Table 2. Correlation data between the Tei index and several echocardiographic parameters in 29 clinically healthy conscious Beagle dogs.

Datos de la correlación entre el índice de Tei y varios parámetros ecocardiográficos en 29 perros Beagles concientes y clínicamente sanos.

\begin{tabular}{lccc}
\hline Parameter & $\mathrm{R}$ & $95 \% \mathrm{CI}$ & $\mathrm{P}$ \\
\hline $\mathrm{LV}_{\mathrm{s}}$ & -0.0603 & $-0.4177,0.3132$ & 0.7559 \\
$\mathrm{LV}_{\mathrm{s}} \cdot \mathrm{m}^{-2}$ & -0.0217 & $-0.3852,0.3476$ & 0.9109 \\
$\mathrm{WSI}_{\mathrm{s}}$ & -0.0103 & $-0.3576,0.3755$ & 0.9576 \\
$\mathrm{LV}_{\mathrm{d}}$ & -0.1659 & $-0.5020,0.2137$ & 0.3897 \\
$\mathrm{LV}_{\mathrm{d}} \cdot \mathrm{m}^{-2}$ & -0.1458 & $-0.4864,0.2333$ & 0.4505 \\
$\mathrm{WSI}$ & -0.0790 & $-0.4331,0.2962$ & 0.6837 \\
$\mathrm{EF}$ & -0.1442 & $-0.4851,0.2348$ & 0.4555 \\
$\mathrm{FS}$ & -0.1361 & $-0.4788,0.2426$ & 0.4814 \\
$\mathrm{LA} / \mathrm{Ao}$ & -0.0935 & $-0.4449,0.2827$ & 0.6294 \\
$\mathrm{E} / \mathrm{A}_{\mathrm{m}}$ & -0.1791 & $-0.5121,0.2006$ & 0.3524 \\
\hline
\end{tabular}

CI: confidence interval; $\mathrm{LV}_{\mathrm{s}}$ : left ventricular internal diameter in systole; $\mathrm{LV}_{\mathrm{d}}$ : left ventricular internal diameter in diastole; $\mathrm{LV}_{\mathrm{s}} \cdot \mathrm{m}^{-2}:$ indexed left ventricular internal diameter in systole; $\mathrm{LV}_{\mathrm{d}} \cdot \mathrm{m}^{-2}$ : indexed left ventricular internal diameter in diastole; WSI $\mathrm{s}$ : wall stress index in systole; WSI $\mathrm{d}_{\mathrm{d}}$ : wall stress index in diastole $\left(\mathrm{WSI}_{\mathrm{d}}\right)$; EF: M-mode derived ejection fraction; FS: fractional shortening; LA/Ao: left atrium-to-aorta ratio; E/A $\mathrm{A}_{\mathrm{m}}$ mitral $\mathrm{E}$ wave-to-A wave ratio.

coefficient of variation for the index calculated for males, females, and all dogs together. Although the mean value of the index appears to be slightly higher in males than in females, no significant difference was attained when data underwent an analysis of variance.

The correlation between the values of the index and several echocardiographic parameters are listed in table 2. No significant correlation was found between the index and the standard echocardiographic measurements that are routinely used as non-invasive measures of cardiac preload, afterload, contractility, and diastolic function.

Also, the index was demonstrated to perform independently of either body weight or heart rate, as shown in figure 3. Pearson's test documented a strong intra-observer and inter-observer correlation coefficient (figure 4).

\section{DISCUSSION}

The aim of this research was not to validate the Tei index, as its reliability has been previously acknowledged, but to quantify the index in healthy non-anesthetized dogs, as well as to investigate whether it correlated with the echocardiographic estimates of loading conditions, cardiac function and remodeling. In this study, the mean value of the Tei index was similar to that reported for healthy dogs in a previous paper, enhancing its reproducibility (Sousa et al 2014).

The Tei index has been investigated in dogs with varying clinical conditions. When evaluating its applicability in Newfoundland dogs with familial dilated cardiomyopathy, Lee et al (2002) found a correlation between the index 


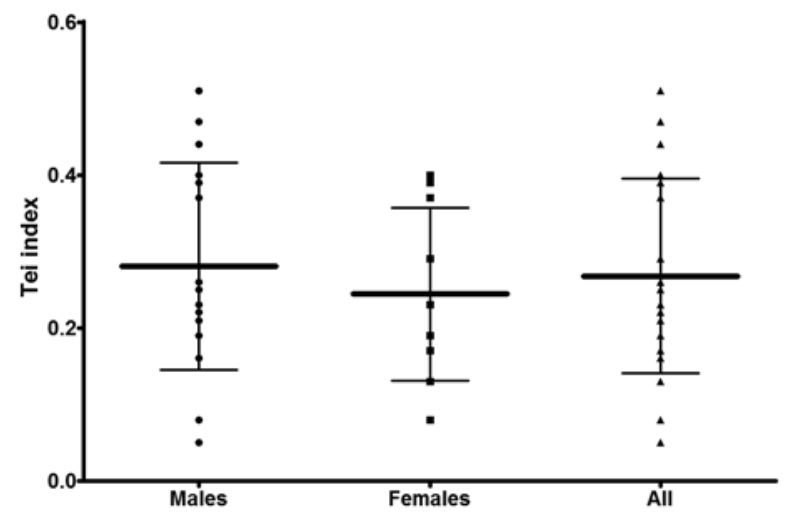

Figure 2. Tei-index of myocardial performance in healthy Beagles $(n=29)$. Bold line and error-bar represent the mean \pm SD. Points represent individual patients.

Índice de rendimiento miocárdico Tei en Beagles clínicamente sanos $(n=29)$. La línea gruesa y la barra de error representan el promedio y la desviación estándar. Los puntos representan los pacientes individuales.
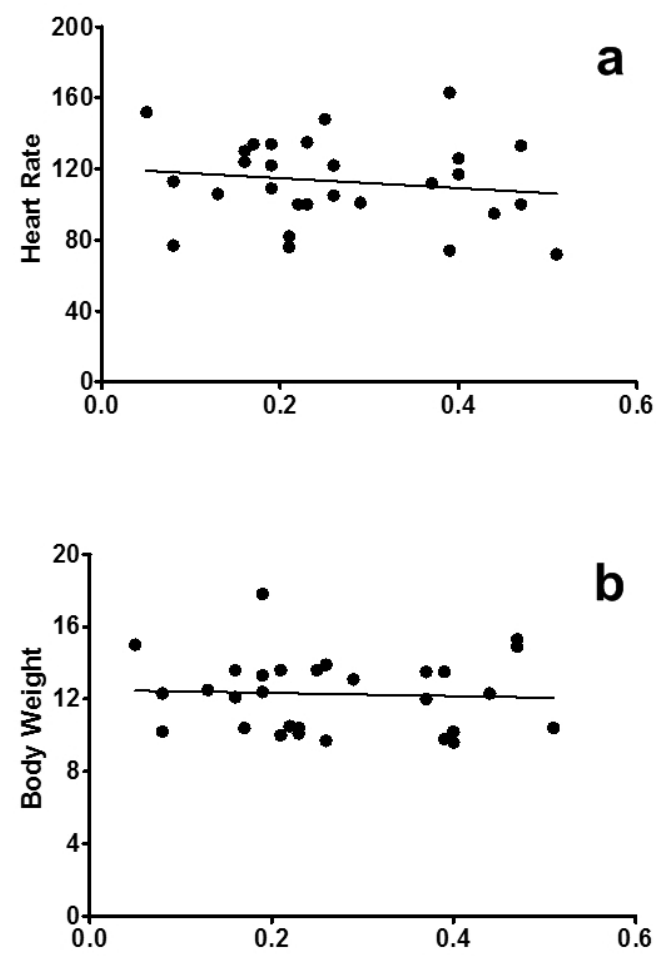

Figure 3. Scatterplots showing non-significant correlation coefficients between the Tei index of myocardial performance and either (a) heart rate $(\mathrm{R}=0.1506, \mathrm{P}=0.4346)$ or $(\mathrm{b})$ body weight $(R=0.0529, P=0.7822)$ in healthy Beagles $(n=29)$. Best-fit lines are shown.

Gráficos de dispersión que muestran los coeficientes de correlación no significativa entre el índice de rendimiento miocárdico de Tei y (a) la frecuencia cardíaca $(\mathrm{R}=0,1506, \mathrm{P}=0,4346)$ o (b) el peso corporal $(\mathrm{R}=0,0529, \mathrm{P}=0,7822)$ en Beagles clínicamente sanos $(\mathrm{n}=29)$.
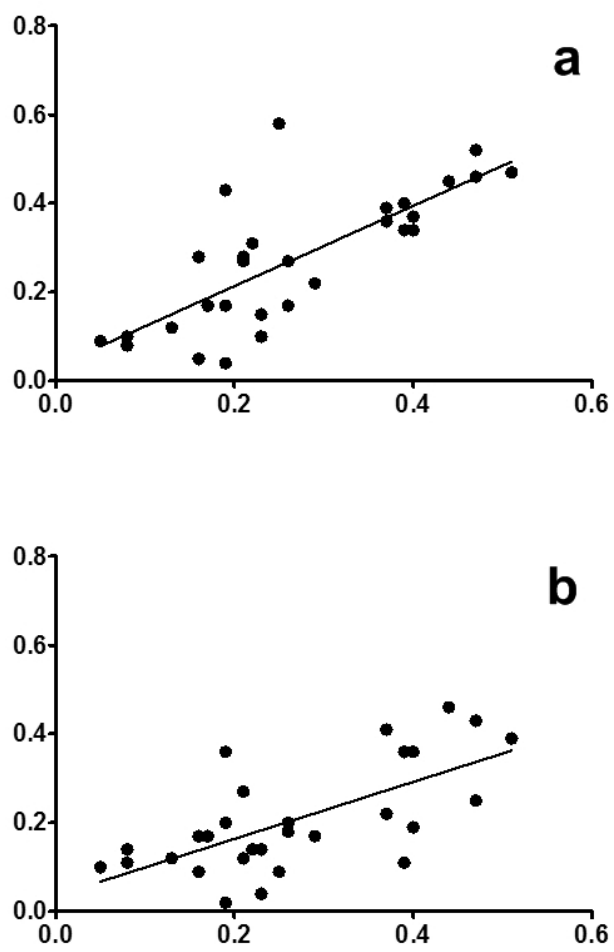

Figure 4. Scatterplots showing significant (a) intra-observer ( $R$ $=0.7573, \mathrm{P}<0.0001)$ and $(\mathrm{b})$ inter-observer $(\mathrm{R}=0.6700, \mathrm{P}<$ $0.0001)$ correlation coefficients for the Tei index of myocardial performance in healthy Beagles $(n=29)$. Best-fit lines are shown.

Gráficos de dispersión que muestran coeficientes de correlación significativa (a) intraobservador $(\mathrm{R}=0,7573, \mathrm{P}<0,0001)$ y (b) entre los observadores $(R=0,6700, P<0,0001)$ para el índice de Tei de rendimiento miocárdico en Beagles clínicamente sanos $(n=29)$.

and the severity of the disease, which might facilitate an early diagnosis. In dogs with myxomatous mitral valve disease, it increased with the progression of clinical signs, apparently because of the shortening of the ejection time resulting from the reduction in forward stroke volume (Teshima et al 2007). In a study in which 16 healthy adult dogs undergoing isoflurane anesthesia were enrolled, the index demonstrated to be a heart rate-independent predictor of impaired global myocardial function (Sousa et al 2007). In another investigation in which doxorubicin was given to seven healthy mature dogs, it was possible to report myocardial toxicity considerably earlier as compared to the standard echocardiographic assessment of cardiac function (Sousa et al 2014). Finally, when the index was investigated in dogs with parvoviral enteritis, it showed the best sensitivity and specificity to differentiate survivors and non-survivors, surpassing cardiac biomarkers, which also included cardiac troponin I (Konkaturk et al 2012). This finding might indicate the usefulness of this index as a non-invasive tool during the diagnostic work-up and prognostic evaluation in septic patients.

In this study, we found no correlation to exist between the index and left ventricular internal diameter in systole 
$\left(\mathrm{LV}_{\mathrm{s}}\right)$ and diastole $\left(\mathrm{LV}_{\mathrm{d}}\right)$, indexed left ventricular internal diameter in systole $\left(\mathrm{LV}_{\mathrm{s}} \cdot \mathrm{m}^{-2}\right)$ and diastole $\left(\mathrm{LV}_{\mathrm{d}} \cdot \mathrm{m}^{-2}\right)$, wall stress index in systole (WSI $)$ and diastole $\left(\mathrm{WSI}_{\mathrm{d}}\right), \mathrm{M}$-mode derived ejection fraction (EF), fractional shortening (FS), left atrium-to-aorta ratio (LA/Ao), and mitral $\mathrm{E}$ wave-to-A wave ratio $\left(\mathrm{E} / \mathrm{A}_{\mathrm{m}}\right)$, which are all load-dependent echocardiographic measurements. Because the index requires isovolumic contraction time, isovolumic relaxation time, and the left ventricular ejection time to be calculated, it allows the assessment of systolic and diastolic function concurrently, therefore being considered a surrogate of global cardiac function (Tei 1995, Pellet et al 2004). Since it performed independently of preload and afterload in this study, it may prove advantageous over the conventional load-dependent parameters that are routinely assessed during the echo examination. Interestingly, contrasting results have been documented as well. In dogs anesthetised with $1.5 \%$ isoflurane the index was able to sensitively detect changes in left-ventricular contractility, but preload and afterload were concluded to play a major role in either decreasing (with increased preload) or increasing (with increased afterload) the index (Uemura et al 2013). Therefore, the limitations of the index must be taken into account especially when the animal's clinical scenario is expected to be associated with a rapidly changing hemodynamic condition.

In addition, no correlation was shown between the Tei index and heart rate. Although some studies have demonstrated that it may be dependent on heart rate (Poulsen et al 2000), previous studies in healthy dogs and in human beings also documented an absence of correlation with such parameter (Sousa et al 2007). More studies are needed to better clarify the dependency of these two measurements, as the influence of heart rate in the Tei index remains controversial and could potentially preclude its use in dogs presenting tachyarrhythmias. Even though a single breed was enrolled in this study, no correlation between the index and body weight could be demonstrated whatsoever.

Also, we sought to investigate the reproducibility of the index having it measured by two operators, as well as having the first sonographer performing a second exam seven days after the first one. The strong inter-observer and intra-observer agreements documented by the correlation test enhance the easy reproducibility of the index, which is particularly important because in serial echocardiograms it could be used to investigate either the deterioration of cardiac function or the response to the therapy by the patient.

The index does fill in a gap for the evaluation of global left cardiac function, because of its non-invasive, straightforward, and reproducible nature. Likewise, several investigators have demonstrated its good correlation with invasive measurements of cardiac function, including an inverse relationship with cardiac output, as well as direct correlation with systolic peak $\mathrm{dP} / \mathrm{dT}$, diastolic peak $\mathrm{dP} /$ dT, and ventricular stiffness (Tei et al 1997, Lacorte et al 2003). Since it was shown to be relatively load-independent, it could be especially useful to evaluate remodeled hearts, in which the altered preload and afterload conditions are likely to interfere with the standard echo parameters used to assess cardiac function, including ejection and shortening fractions. Although the Tei index has been mostly used as an indicator of left ventricular function, Baunwart et al (2005) reported its use to assess the right ventricle, with the normal values being consistently lower than those calculated from the left ventricle in healthy dogs.

The absence of animals with cardiac disease is the major weakness of this study. It precluded a detailed investigation of how the index performs under altered loading conditions and/or impaired cardiac function. Nonetheless, this large population of isogenic dogs allowed to determine a reference range for normal subjects that may be used as a standard in other studies.

In conclusion, this study brought information on normal values of the Tei index of myocardial performance in healthy conscious dogs and also documented their heart rate and body weight independency. The lack of significant correlation between the index and the echocardiographic data might be supportive of its preload and afterload independency, since all echo parameters investigated herein are influenced by loading conditions, which are likely altered in dogs with failing hearts. Further studies are warranted to examine this non-invasive parameter in dogs with impaired cardiac function.

\section{REFERENCES}

Baumwart RD, KM Meurs, JD Bonagura. 2005. Tei Index of myocardial performance applied to the right ventricle in normal dogs. $J$ Vet Intern Med 19, 828-832.

Ishi M, T Tsutsumi, W Himeno, G Eto, J Furui, K Hashino, Y Sugahara, H Muta, T Akagi, A Ando, H Eguchi, H Kato. 2000. Sequential evaluation of left ventricular myocardial performance in children after anthracycline therapy. Am J Cardiol 86, 1279-1281.

Kocaturk M, S Martinez, O Eralp, A Tvarijonaviciute, J Ceron, Z Yilmaz. 2012. Tei index (myocardial performance index) and cardiac biomarkers in dogs with parvoviral enteritis. Res Vet Sci 92, 24-29.

Lacorte JC, SE Cabreriza, DG Rabkin, BF Printz, L Coku, A Weinberg, WM Gersony, HM Spotnitz. 2003. Correlation of the Tei index with invasive measurements of ventricular function in a porcine model. J Am Soc Echocardiogr 16, 442-447.

Lakoumentas JA, FK Panou, VK Kotseroglou, KI Aggeli, PK Harbis. 2005. The Tei index of myocardial performance: applications in cardiology Hellenic J Cardio 46, 52-58

Lee BH, JD McEwan, AT French, BM Corcoran. 2002. Evaluation of a novel doppler index of combined systolic and diastolic myocardial performance in newfoundland dogs with familial prevalence of dilated cardiomyopathy. Vet Radiol Ultrasoun 43 2, 154-165.

Madron E. 2015. Normal echocardiographic values: TM, 2D, and doppler spectral modes. In: Chetboul V, Bussadori C, Madron E (eds). Clinical echocardiography of the dog and cat. Elsevier, Saint Louis, USA, Pp 21-32.

Mooradian S, C Goldberg, D Crowle, A Ludomirsky. 2000. Evaluation of a noninvasive index of global ventricular function to predict rejection after pediatric cardiac transplantation. Am J Cardiol 86, 358-360.

Pellett A, WG Tolar, BS Merwin, EK Kerut. 2004. The Tei index: methodology and disease state values. Echocardiography 21, 669-672.

Poulsen SH, JC Nielsen, HR Andersen. 2000. The influence of heart rate on the Doppler-derived myocardial performance index. J Am Soc Echocardiogr 3, 379-384. 
Sousa MG, R Carareto, AB De-Nardi, FL Brito, N Nunes, AA Camacho. 2007. Effects of isoflurane on Tei-index of myocardial performance in healthy dogs. Can Vet J 48, 277-283.

Sousa MG, D Paulino-Junior, JPE Pascon, GB Pereira-Neto, R Carareto, AA Camacho. 2014. Assesment of the TEI index of myocardial performance in dogs with doxorubicin-induced cardiomiopathy Arch Med Vet 46, 63-68.

Tei C. 1995. New non-invasive index for combined systolic and diastolic ventricular function. J Cardiol 26, 135-136.

Tei C, RA Nishimura, JB Seward, AJ Tajik. 1997. Noninvasive Dopplerderived myocardial performance index: Correlation with simultaneous measurements of cardiac catheterization measurements. J Am Soc Echocardiogr 10, 169-178.

Teshima K, K Asano, K Iwanaga, H Koie, M Uechi, Y Kato, K Kutara, N Kanno, M Seki, K Edamura, A Hasegawa, S Tanaka. 2007. Evaluation of left ventricular Tei Index (Index of Myocardial Performance) in healthy dogs and dogs with mitral regurgitation. J Vet Med Sci 69, 117-123.

Uemura K, T Kawada, C Zheng, M Li, T Shishido, M Sugimachi. 2013. Myocardial performance index is sensitive to changes in cardiac contractility, but is also affected by vascular load condition. Proceedings of the $35^{\text {th }}$ Annual International Conference of the IEEE, Osaka, Japan, Pp 695-698. 